\title{
Chlorination Treatment of Meta-Aramid Fibrids and Its Effects on Mechanical Properties of Polytetramethylene Ether Glycol/Toluene Diisocyanate (PTMEG/TDI)-Based Polyurethane Composites
}

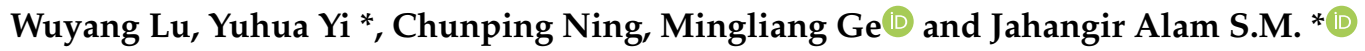 \\ Department of Industrial Equipment and Control Engineering, School of Mechanical \& Automotive Engineering, \\ South China University of Technology, Guangzhou 510640, China; luwuyang1682@163.com (W.L.); \\ ningchp@163.com (C.N.); gml@scut.edu.cn (M.G.) \\ * Correspondence: mmyhyi@scut.edu.cn (Y.Y.); mejahangir@scut.edu.cn (J.A.S.M.); \\ Tel.: +86-1325-025-4060 (J.A.S.M)
}

Received: 24 September 2019; Accepted: 24 October 2019; Published: 1 November 2019

\begin{abstract}
Meta-aramid fibrids (MAF) have attracted much attention. However, it is difficult for this high mechanical performance fiber to form sufficient interface adhesion between the MAF and polyurethane (PU) matrix due to the chemical inertness of its surface. Thus, the surface activity of MAF should be improved to obtain a high-performance MAF/PU composite. A novel methodology to modify the surface of MAF with a sodium dichloroisocyanurate solution (DCCNa) was developed to obtain chlorinated MAF (MAFC) in this study. A series of MAFC/PU composites was prepared by in situ polymerization processes. The results of Fourier-transform infrared spectroscopy (FTIR) and X-ray photoelectron spectroscopy (XPS) demonstrated that the chlorine-contained chemical groups were introduced onto the MAF surfaces after chlorination. Dynamic contact angle analysis (DCAA) revealed that the surface wettability and the surface free energy of the MAFC were significantly improved, which allowed for strong chemical bonding to PU. Scanning electron microscopy (SEM) showed a uniform distribution of MAFC and good interfacing bonding between the MAFC and $\mathrm{PU}$. With the incorporation of $1.5 \mathrm{wt} \%$ MAFC into the polyurethane matrix, the tensile and tear strength values of MAFC/PU were $36.4 \mathrm{MPa}$ and $80.1 \mathrm{kN} \cdot \mathrm{m}^{-1}$ respectively, corresponding to improvements of approximately $43.3 \%$ and $21.1 \%$, as compared to those of virgin PU as $25.4 \mathrm{MPa}$ and $66.1 \mathrm{kN} \cdot \mathrm{m}^{-1}$, respectively.
\end{abstract}

Keywords: chlorination; meta-aramid fibrids; PTMEG/TDI; polyurethane composites

\section{Introduction}

It has been reported that polytetramethylene ether glycol/toluene diisocyanate(PTMEG/TDI)-based polyurethane (PU) elastomer is a block copolymer composed of alternating soft and hard segment phase, wherein the hard segment phase is composed of toluene diisocyanate (TDI) and a chain extender, and the soft segment phase is composed of polytetramethylene ether glycol (PTMEG) [1]. In the molecular structure of PTEMG, four methylene groups are regularly arranged between ether bonds and endow to form a semi-crystalline polymer [2,3]. Therefore, polyurethane elastomers prepared with PTMEG are widely used in dynamically demanding applications such as rolls, tires, and wheels because of their relatively high resistance to hydrolytic cleavage, high resilience, high wear resistance, good low-temperature flexibilities, good processabilities, and superior dynamic performance [4]. 
However, PTMEG/TDI-based PU elastomer cannot be used in high-load applications due to the insufficient mechanical strength of the PTMG2000/TDI polyurethane elastomer, here PTMEG2000 refers to the PTMEG with the average molecular weight of 2000. Thus, the mechanical properties of PTMEG/TDI-based PU elastomers should be improved.

In recent years, a variety of appropriate fiber fillers had been incorporated into polyurethane significantly improved the mechanical properties, including jute fibers [5], natural cellulose fibers [6], hemp fibers [7], carbon fibers [8], fiberglass [9], and aramid fibers [10]. The other researchers had defined that the meta-aramid fibrids (MAF) are a kind of aramid fiber prepared through precipitation by injecting the meta-aramid solution into a high-shear coagulation bath [11,12]. The MAF is a ribbon-like material with an average length of $0.2-1 \mathrm{~mm}$, an aspect ratio ranging from 1000 to 3000, and a thickness less than $2 \mu \mathrm{m}$. Thus, MAF possesses large specific surface areas [13,14]. MAF also possesses the inherent properties of meta-aramid fibers, such as higher strength, higher modulation, and excellent thermal and chemical stabilities. As a result, MAF is widely used in high-temperature materials and honeycomb-structure materials.

Although MAF possesses many excellent properties, due to the surface chemical inertness and the steric effect of the benzene rings in the molecular chains, the amide groups of MAF do not react readily with other atoms or groups, which results in poor interface adhesion between the MAF and polyurethane matrix $[15,16]$. Therefore, it is vital to modify the surfaces of MAF to improve the interface adhesion with the matrix. The chemical modification is a relatively common surface treatment method for aramid fibers, which can improve the surface polarity of aramid fibers by introducing reactive groups and elements onto the surfaces of aramid fibers [17]. According to the literature, the chemical modification methods based on strong acid modification include phosphoric acid modification $[15,17,18]$, fluorination modification [19,20], chlorination modification [21], and so on.

In this study, we used sodium dichloroisocyanurate (DCCNa) as a high-efficiency chlorination treatment agent for MAF to obtain chlorinated MAFC. MAF/PU and MAFC/PU composites were prepared by in situ polymerizations. The MAF and MAFC were characterized by Fourier-transform infrared spectroscopy (FTIR), X-ray photoelectron spectroscopy (XPS), dynamic contact angle measurements and scanning electron microscopy (SEM). The mechanical properties of the MAF/PU and MAFC/PU composites were characterized using tensile testing.

\section{Materials and Methods}

\subsection{Materials}

The meta-aramid fibrids (MAF) were supplied by Guangdong Feibo New Material Technology Co. Ltd., Yunfu, Guangdong, China; the 2,4-toluene diisocyanate (TDI-100) was purchased from Mitsui Chemicals, Inc, Tokyo, Japan; the polytetramethylene ether glycol (PTMEG, $M n=2000$ ) was provided by the Mitsubishi Chemical Corporation, Kyoto, Japan; the 3,3'-dichloro-4,4'-diaminodiphenylmethane (MOCA) was obtained from the Suzhou Xiangyuan Special Fine Chemical Co. Ltd., Suzhou, Jiangsu, China. The raw materials were all industrial grade. Analytical grade ethyl acetate (EA) was supplied by the Shanghai Ourchem Biotechnology Co., Ltd., Shanghai, China. Sodium dichloroisocyanurate (DCCNa) was provided by the Jinan Delan Chemical Co., Ltd., Jinan, Shandong, China.

\subsection{Chlorination Treatment of $M A F$}

The surfaces of MAF were cleaned with an ethyl acetate (EA) solution. To achieve a better cleaning effect, the mixed solution of MAF and EA were dispersed at $4000 \mathrm{rpm}$ for $15 \mathrm{~min}$ using a high-speed disperser. The MAF was subsequently extracted by a vacuum filtration device. The MAF was cleaned two to three times using this method, and the MAF were fully dried in an oven at $110{ }^{\circ} \mathrm{C}$ for $4 \mathrm{~h}$. The dried MAF was dispersed by a high-shear force using a 2800-rpm high-speed pulverizer. The dispersed MAF was added to a 10\% DCCNa solution, and after manual stirring for $5 \mathrm{~min}$, the DCCNa solution was suction filtered. The MAF was cleaned with distilled water several 
times until the surface $\mathrm{pH}$ value of the MAF was neutral. The modified MAF (MAFC) was dried in the oven at $110^{\circ} \mathrm{C}$ for $12 \mathrm{~h}$.

\subsection{Preparation of $M A F C / P U$ Composites}

MAFC/PU composites were prepared by in situ polymerizations. First, the pretreated MAFC was added to the PTMEG2000 and dispersed at $4000 \mathrm{rpm}$ for $15 \mathrm{~min}$ using a high-shear mixture. The mixture was added to a three-necked flask equipped with a stirring system, a vacuum system, and a thermometer. Vacuum dehydration of the mixture was performed at $110{ }^{\circ} \mathrm{C}$ for $2-3 \mathrm{~h}$. When the moisture content of the mixture was less than $0.05 \%$, as detected by a Karl Fischer Moisture Analyzer, the calculated TDI was added into the mixture and reacted at $(80 \pm 2)^{\circ} \mathrm{C}$ for $2 \mathrm{~h}$ to obtain a prepolymer. The NCO group content of the prepolymer was measured. Finally, the MOCA (which is called a chain extender, melted at $115 \pm 3^{\circ} \mathrm{C}$ ) was added to the prepolymer, which was preheated to $80 \pm 2{ }^{\circ} \mathrm{C}$ in advance; then, the mixture was rapidly stirred for 1-2 $\mathrm{min}$, and poured into molds that were preheated to $110^{\circ} \mathrm{C}$ in advance. After vulcanizing on a plate vulcanizing machine for $1 \mathrm{~h}$, the MAFC/PU composite samples were taken out and placed in an electric blast drying oven at $100^{\circ} \mathrm{C}$ for $20 \mathrm{~h}$. The formulations of MAF/PU and MAFC/PU composites with different ratios of filler have been summarized in Table 1.

Table 1. Formulations of polyurethane (PU) composites.

\begin{tabular}{ccc}
\hline Sample Code & MAF/wt $\%$ & MAFC/wt $\%$ \\
\hline PU & - & - \\
PU-F-0.5 & 0.5 & - \\
PU-F-1 & 1 & - \\
PU-F-1.5 & 1.5 & - \\
PU-FC-0.5 & - & 0.5 \\
PU-FC-1 & - & 1 \\
PU-FC-1.5 & - & 1.5 \\
PU-FC-2 & - & 2 \\
\hline
\end{tabular}

$\mathrm{F}$ and FC refer to MAF and MAFC respectively.

\subsection{Characterization}

SEM was conducted to investigate the morphologies of the MAF and MAFC using a Quanta FEG 250 scanning electron microscope (FEI, Hillsboro, OR, USA) operating under secondary electron mode at an accelerating voltage of $5 \mathrm{kV}$. The FTIR spectra of the MAF and MAFC were recorded on a Vertex-70 (Bruker, Karlsruhe, Germany) spectrometer with an attenuated total reflectance (ATR) in the scanning range of 500-4000 $\mathrm{cm}^{-1}$. XPS was performed to analyze the surface element change of the MAF and MAFC using an Axis Ultra DLD X-ray photoelectron spectrometer (Kratos Analytical, Manchester, UK) with a monochromatic Al K $\alpha$ source (1486.6 eV).

The surface free energy and contact angles of the MAF and MAFC were evaluated using an OCA40 micro-dynamic contact angle analysis system (Data Physics Instruments, GmbH, Filderstadt, Germany). The surface free energy of the MAF and MAFC were measured using deionized water $\left(\gamma_{L}^{d}=21.8 \mathrm{mN} / \mathrm{m}, \gamma_{L}^{p}=51 \mathrm{mN} / \mathrm{m}\right.$, and $\left.\gamma_{L}=72.8 \mathrm{mN} / \mathrm{m}\right)$ and ethylene glycol $\left(\gamma_{L}^{d}=29.3 \mathrm{mN} / \mathrm{m}\right.$, $\gamma_{L}^{p^{L}}=19 \mathrm{mN} / \mathrm{m}$, and $\gamma_{L}=48.3 \mathrm{mN} / \mathrm{m}$ ) as testing liquids. The surface free energy can be calculated from the following Equations [22,23]:

$$
\begin{gathered}
\gamma_{L}(1+\cos \theta)=2 \sqrt{\gamma_{L}^{d} \gamma_{S}^{d}}+2 \sqrt{\gamma_{L}^{p} \gamma_{S}^{p}} \\
\gamma_{S}=\gamma_{S}^{d}+\gamma_{S}^{p}
\end{gathered}
$$

where $\theta$ is the contact angle at the solid/liquid interface, and $\gamma_{L}$ and $\gamma_{S}$ are the surface tension of the testing liquid and fibrids, respectively. $\gamma_{L}^{d}$ and $\gamma_{L}^{p}$ are the polar and dispersive components of the 
surface tension of the testing liquid, respectively. $\gamma_{S}^{d}$ and $\gamma_{S}^{p}$ represent the polar component and the dispersive component of the total surface free energy of the fibrids, respectively [22,23].

Tensile tests of the composite samples were measured using an LD-24.104 electromechanical universal testing machine (LABSANS, Shenzhen, China). The measurements of the tensile strength and elongation at break were based on the ASTM D412 standard, and the rate of the extension was $500 \mathrm{~mm} / \mathrm{min}$. The tear strength was measured according to ASTM D624. Measurements of the hardness values of the composite samples were performed using an LX-A Model Hardness Meter (Shanghai Precision Instruments Co. Ltd., Shanghai, China) according to the ASTM D2240 standard; the rebound rate was measured using a WT B-0.5 impact testing machine according to the ASTM D2632 standard. The morphologies of the polyurethane composites were investigated using a Quanta FEG 250 SEM (FEI, Hillsboro, OR, USA).

\section{Results and Discussion}

\subsection{Surface Morphologies of MAF and MAFC}

Figure 1 shows the SEM images of original fibrids (MAF) and modified fibrids (MAFC). As shown in Figure 1a,b, the original MAF was irregular ribbon-like or film-like materials due to the high-shear coagulation bath. The MAF had an average length of $0.2-1 \mathrm{~mm}$ with aspect ratios of 5:1-10:1. The thickness was less than 1-2 $\mu \mathrm{m}$. Therefore, the MAF possessed large specific surface areas of soft shape and excellent flexibility but excellent toughening and mechanical properties. However, Figure $1 \mathrm{a}, \mathrm{b}$ exhibits a rather smooth surface of MAF. By contrast, Figure $1 \mathrm{c}, \mathrm{d}$ shows that the surface of MAFC became slightly rough, implying that the surfaces of MAF were successfully activated by the chlorination treatment.
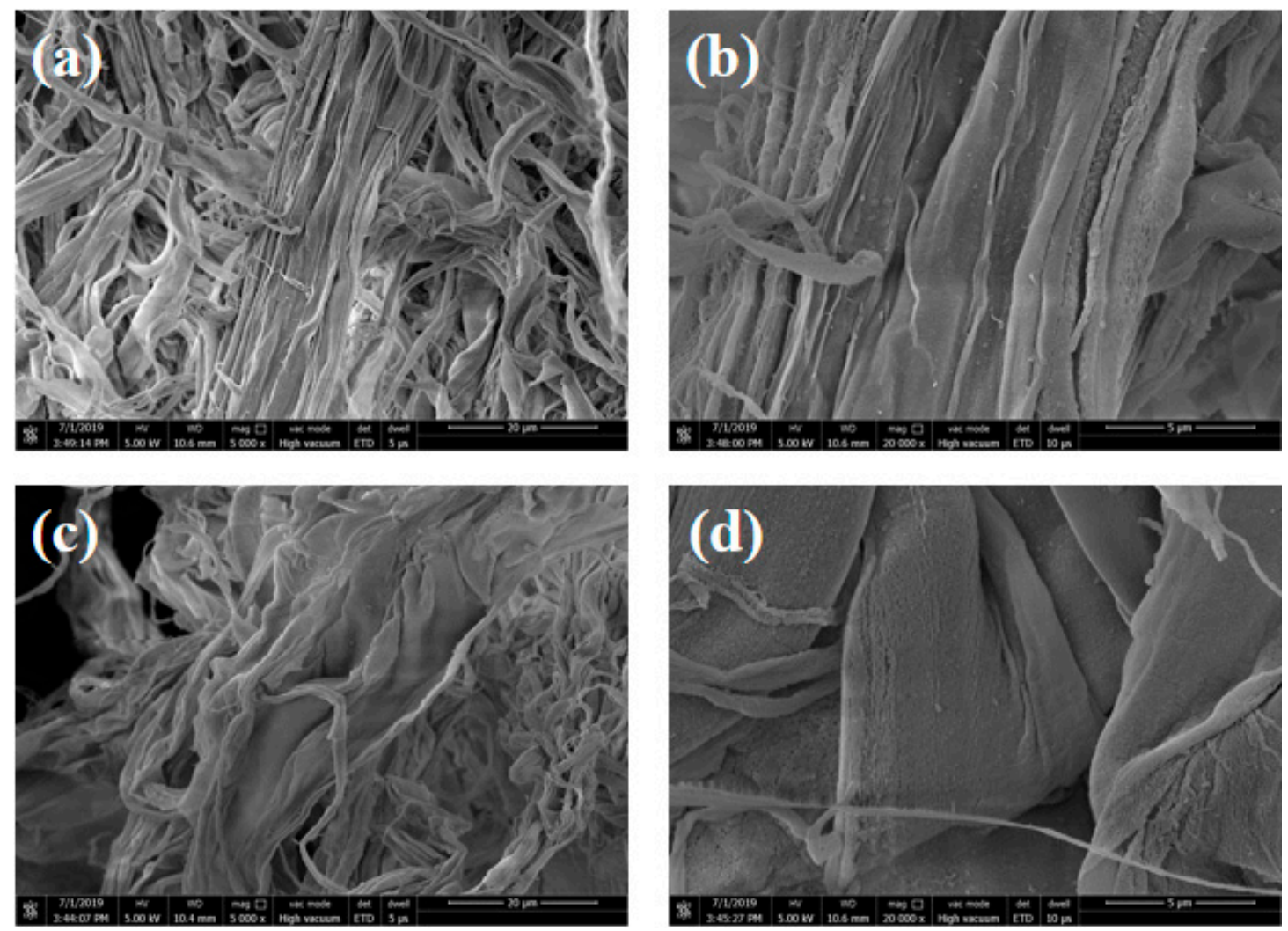

Figure 1. SEM images of original and modified fibrids; (a,b) meta-aramid fibrids (MAF), and (c,d) chlorinated MAF (MAFC). 


\subsection{IR Analysis}

Figure 2 shows the FTIR spectra of MAF, DCCNa, and MAFC. The molecular structures of MAF, DCCNa, and MAFC were characterized by FTIR analysis. As shown in Figure 2, the characteristic absorption peaks of the MAF at $3415 \mathrm{~cm}^{-1}$ and $3060 \mathrm{~cm}^{-1}$ have corresponded to the $\mathrm{N}-\mathrm{H}$ and aromatic C-H stretching vibrations, respectively, the vibration peaks of $1660 \mathrm{~cm}^{-1}, 1608 \mathrm{~cm}^{-1}$, and $1540 \mathrm{~cm}^{-1}$ were attributed to $\mathrm{C}=\mathrm{O}$ stretching vibrations, aromatic $\mathrm{C}=\mathrm{C}$ stretching vibrations, and $\mathrm{N}-\mathrm{H}$ deformation vibrations in MAF, respectively [11,24]. The characteristic peaks of DCCNa at $1742 \mathrm{~cm}^{-1}, 1355 \mathrm{~cm}^{-1}$, and $700 \mathrm{~cm}^{-1}$ were assigned to $\mathrm{C}=\mathrm{O}, \mathrm{C}-\mathrm{N}$ and $\mathrm{N}-\mathrm{Cl}$ stretching vibrations, respectively. The new absorption peaks at approximately 3215 and $1753 \mathrm{~cm}^{-1}$ in the MAFC have corresponded to the $-\mathrm{NH}_{2}$ symmetrical stretching vibrations, and $\mathrm{C}=\mathrm{O}$ stretching vibrations of $-\mathrm{COOH}$, respectively, which indicated that hydrolysis reactions occurred on the surfaces of the MAFC during the chlorination modification. Furthermore, the new vibration peaks at approximately $530 \mathrm{~cm}^{-1}$ and $750 \mathrm{~cm}^{-1}$ for the MAFC corresponded to $\mathrm{N}-\mathrm{Cl}$ stretching vibrations due to $\mathrm{N}$-chlorination of the amidic nitrogen after the chlorination treatment. Lastly, the new peak at $1052 \mathrm{~cm}^{-1}$ was assigned to $\mathrm{C}-\mathrm{Cl}$ vibrations, which was due to the Orton rearrangement of partially chlorinated $N[25,26]$. The entire chlorination treatment mechanism is illustrated in Figure 3.

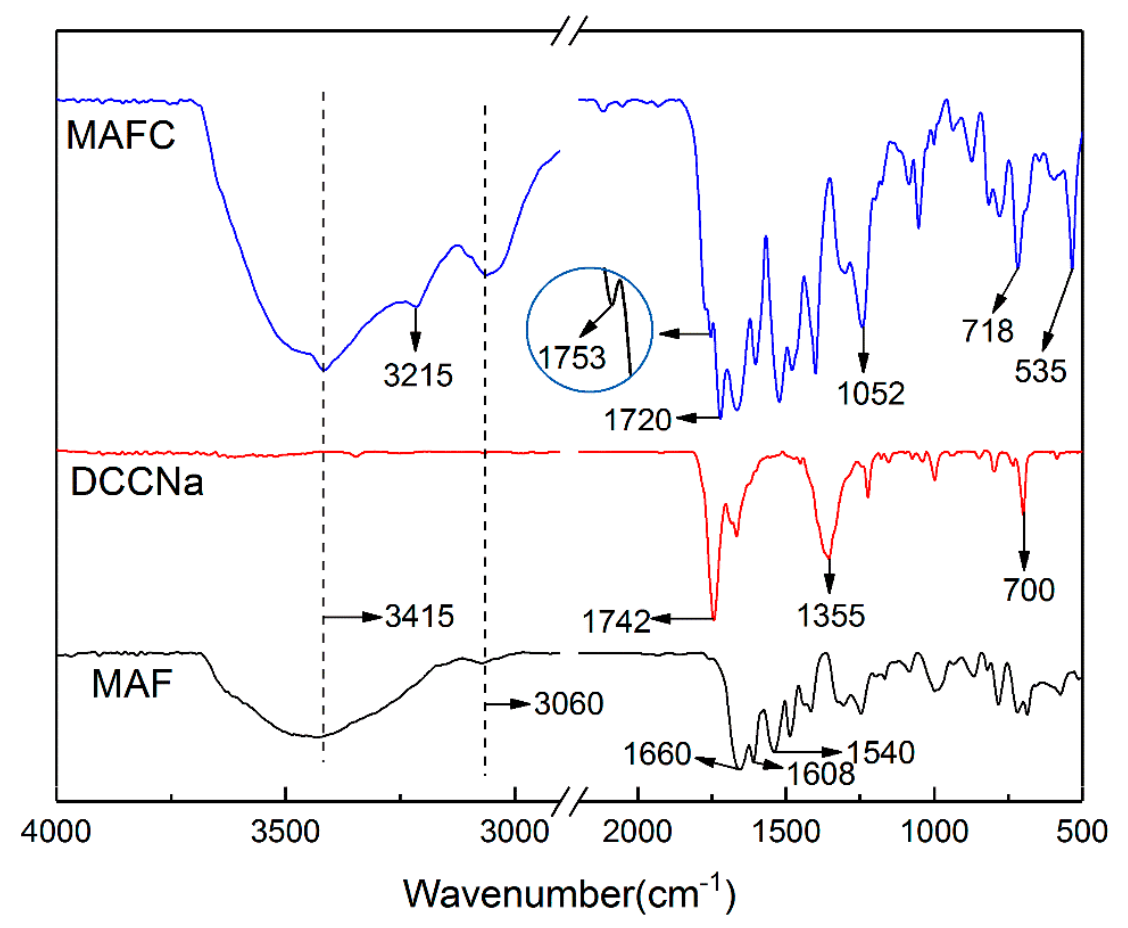

Figure 2. Fourier-transform infrared spectroscopy (FTIR) spectra of MAF, sodium dichloroisocyanurate solution (DCCNa), and MAFC. 
<smiles>N#CC1(O)C(=O)N(Cl)C(=O)N(Cl)C1=O</smiles>

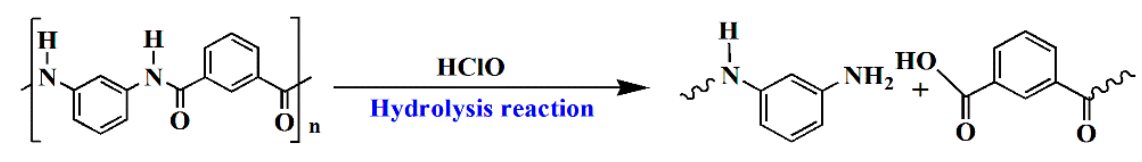

MAF

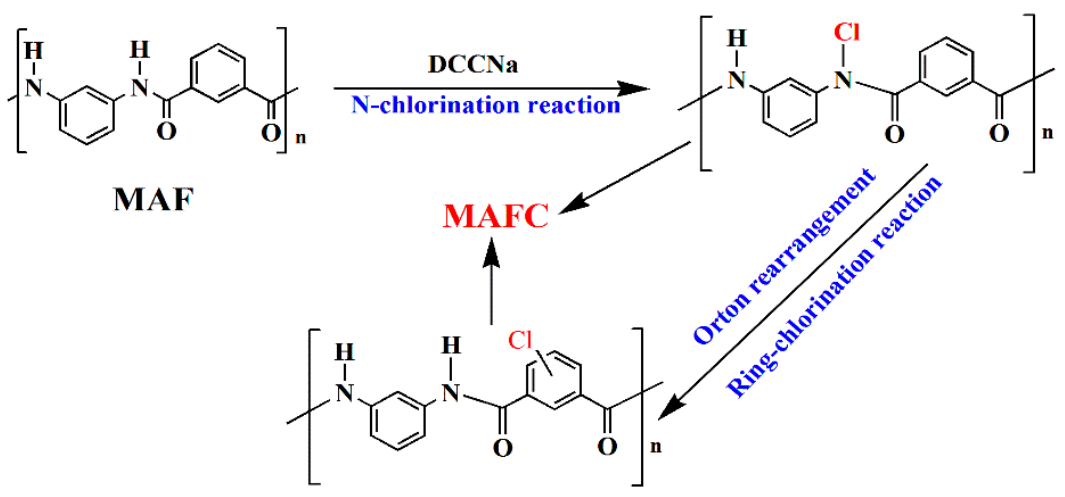

Figure 3. Mechanism of chlorination treatment in MAFC.

\subsection{Surface Chemical Composition of MAF and MAFC}

Figure 4 shows the XPS wide-scan spectra and $\mathrm{Cl} 2 \mathrm{p}$ spectra of the MAF and MAFC. To demonstrate the mechanism of the chlorination treatment of the fibrids, XPS was used to investigate the chemical surface composition of MAF and MAFC. As shown in Figure 4 and Table 2, the MAF and MAFC contained inherent oxygen, nitrogen, and carbon elements. In addition, the presence of chlorine in the MAFC indicated that the MAF was chlorinated. The surface elemental analysis results for the MAF and MAFC are listed in Table 2. The chlorine contents of the MAF and MAFC were found 0 and $7.9 \%$, respectively. It was also demonstrated that the chlorine was attached to the surfaces of MAF after chlorination modification. Compared with the MAF, it apparently decreased from $80.9 \%$ to $70.2 \%$ of carbon $(\mathrm{C})$ concentration; and oxygen $(\mathrm{O})$ concentration was increased from $9.6 \%$ to $12.7 .7 \%$ with the increase in the oxygen/carbon $(\mathrm{O} / \mathrm{C})$ atomic ratio from 0.119 to 0.181 ; Furthermore, the nitrogen $(\mathrm{N})$ concentration decreased slightly from $9.5 \%$ to $9.2 \%$ when the nitrogen/carbon $(\mathrm{N} / \mathrm{C})$ atomic ratio increased from 0.118 to 0.131 . The increase in the $\mathrm{N} / \mathrm{C}$ and $\mathrm{O} / \mathrm{C}$ atomic ratios indicated that new polar chemical groups $\left(-\mathrm{COOH}\right.$ and $-\mathrm{NH}_{2}$ ) were introduced to the MAFC surfaces by the chlorination treatment. To ascertain the state of chlorine $(\mathrm{Cl})$ in the MAFC molecular structure after chlorine $(\mathrm{Cl})$ treatment, the peaks of $\mathrm{Cl}(2 \mathrm{p})$ were further investigated in Figure $4 \mathrm{~d}$. The $\mathrm{Cl}(2 \mathrm{p})$ spectrum of the MAFC was curve fit with four peaks at binding energies of approximately $200.15 \mathrm{eV}, 200.74 \mathrm{eV}$, $201.45 \mathrm{eV}$, and $202.35 \mathrm{eV}$ [27]. The fit peaks at $200.15 \mathrm{eV}$ and $200.74 \mathrm{eV}$ were attributed to the $\mathrm{Cl}\left(2 \mathrm{p}^{1 / 2}\right)$, and $\mathrm{Cl}\left(2 \mathrm{p}^{3 / 2}\right)$ of $\mathrm{O}=\mathrm{C}-\mathrm{N}-\mathrm{Cl}$, respectively. However, the fit peaks at approximately $201.45 \mathrm{eV}$ and $202.35 \mathrm{eV}$ corresponded to the $\mathrm{Cl}\left(2 \mathrm{p}^{1 / 2}\right)$ and $\mathrm{Cl}\left(2 \mathrm{p}^{3 / 2}\right)$ of $\mathrm{C}_{6} \mathrm{H}_{5} \mathrm{Cl}$, respectively, which indicated that $\mathrm{O}=\mathrm{C}-\mathrm{N}-\mathrm{Cl}$ have been formed by $\mathrm{N}$-chlorination of the amidic nitrogen, and that $\mathrm{C}_{6} \mathrm{H}_{5} \mathrm{Cl}$ formed due to the Orton rearrangement of $\mathrm{O}=\mathrm{C}-\mathrm{N}-\mathrm{Cl}$ during the chlorine treatment $[28,29]$. 

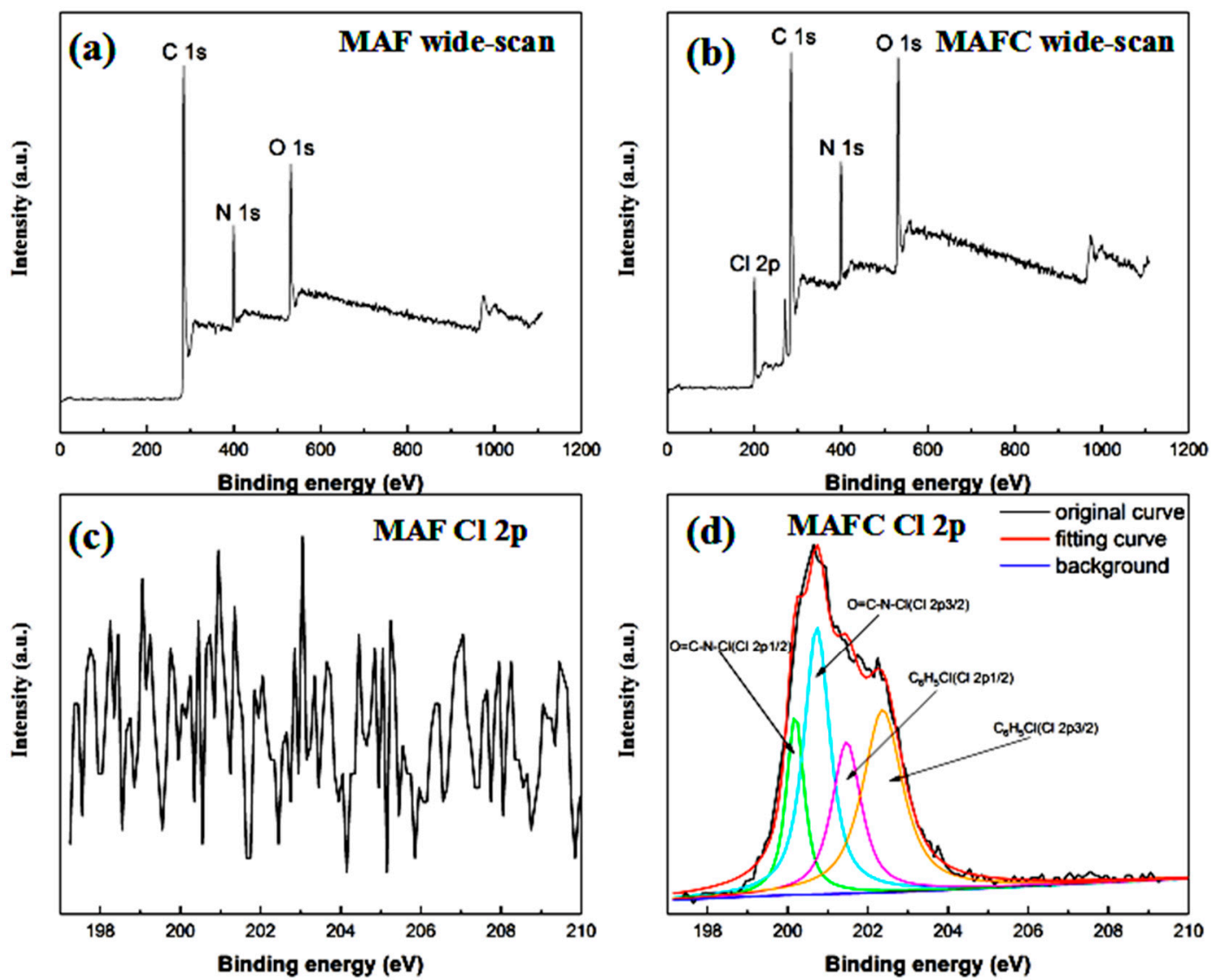

Figure 4. X-ray photoelectron spectroscopy (XPS) wide-scan spectra and Cl 2p spectra of (a,c) MAF and $(\mathbf{b}, \mathbf{d})$ MAFC.

Table 2. XPS surface element analysis of MAF before and after treatment.

\begin{tabular}{ccccccc}
\hline \multirow{2}{*}{ Samples } & \multicolumn{3}{c}{ Chemical Composition [\%] } & \multicolumn{2}{c}{ Atomic Ratio } \\
\cline { 2 - 7 } & $\mathbf{C}$ & $\mathbf{N}$ & $\mathbf{O}$ & $\mathbf{C l}$ & O/C & N/C \\
\hline MAF & 80.9 & 9.5 & 9.6 & 0 & 0.119 & 0.118 \\
MAFC & 70.2 & 9.2 & 12.7 & 7.9 & 0.181 & 0.131 \\
\hline
\end{tabular}

\subsection{Surface Wettability of MAF and MAFC}

Figure 5 shows the water, ethylene glycol, and PU prepolymer contact angle of the MAF and MAFC. It is well known that the surface treatment of the filler plays an important role in the formation of an excellent interface with the matrix. To study the changes of the surface energies of the MAF and MAFC caused by the surface treatment, the surface wettability and surface energy of the MAF and MAFC were analyzed by contact angle measurements. The contact angles of the MAF were found to be $94.6^{\circ}$ and $72.5^{\circ}$ with deionized water and ethylene glycol, respectively. The water and ethylene glycol contact angles of the MAFC were found at $51.2^{\circ}$ and $35.7^{\circ}$, respectively, indicating that the surface wettability of the MAFC was improved after the chlorination treatment. 

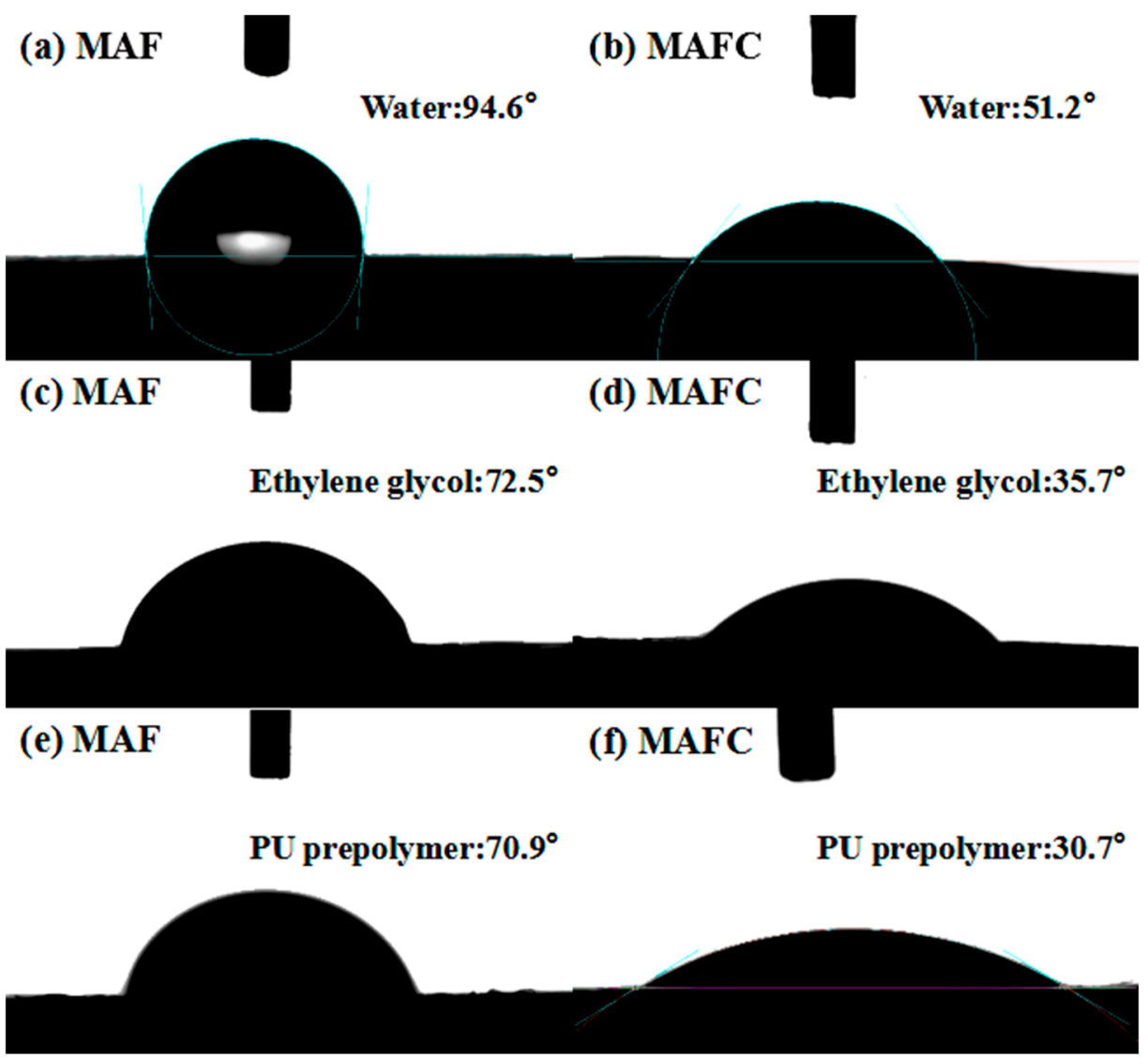

Figure 5. Water, ethylene glycol, and PU prepolymer contact angles of $(\mathbf{a}, \mathbf{c}, \mathbf{e}) \mathrm{MAF}$ and $(\mathbf{b}, \mathbf{d}, \mathbf{f}) \mathrm{MAFC}$.

The change of the surface energies of the MAF and MAFC, as summarized in Table 3, exhibited similar trends to those of the contact angle. The $21.9 \mathrm{~mJ} / \mathrm{m}^{2}$ total surface energy $\left(\gamma_{S}\right)$ of the MAF was composed of a $3.6 \mathrm{~mJ} / \mathrm{m}^{2}$ polar component $\left(\gamma_{S}^{p}\right)$ and a $18.3 \mathrm{~mJ} / \mathrm{m}^{2}$ dispersive component $\left(\gamma_{S}^{d}\right)$. However, the total surface energy $\left(\gamma_{S}\right)$ of the MAFC increased to $49.1 \mathrm{~mJ} / \mathrm{m}^{2}$, which consisted of a $40.3 \mathrm{~mJ} / \mathrm{m}^{2}$ polar component $\left(\gamma_{S}^{p}\right)$ and a $8.8 \mathrm{~mJ} / \mathrm{m}^{2}$ dispersive component $\left(\gamma_{S}^{d}\right)$ after the chlorination treatment. The surface polar component $\left(\gamma_{S}^{p}\right)$ of the MAFC has exhibited a drastic improvement from 3.6 to $40.3 \mathrm{~mJ} / \mathrm{m}^{2}$; this improvement was attributed to the presence of polar functional groups, such as $-\mathrm{Cl}-$, $-\mathrm{COOH}$, and $-\mathrm{NH}_{2}$, which were incorporated on the surfaces of the MAFC after chlorination treatment. In addition, the PU prepolymer contact angles before chlorination and after modified chlorination decreased from $70.9^{\circ}$ to $30.7^{\circ}$, as shown in Figure 5e,f, illustrating that the wettability and interfacial bonding of the fibrids and PU matrix improved after chlorination modification.

Table 3. Contact angles and surface free energy of MAF and MAFC.

\begin{tabular}{ccccccc}
\hline \multirow{2}{*}{ Samples } & \multicolumn{2}{c}{ Contact Angle $\boldsymbol{\theta} \pm \mathrm{SD}^{\#}\left(^{\circ}\right)$} & & \multicolumn{2}{c}{ Surface Free Energy $\left(\mathbf{m J} / \mathbf{m}^{\mathbf{2}}\right)$} \\
\cline { 2 - 3 } \cline { 5 - 6 } & Water & Ethylene Glycol & & $\gamma_{S}^{d}$ & $\gamma_{S}^{p}$ & $\gamma_{S}=\gamma_{S}^{d}+\gamma_{S}^{p}$ \\
\hline MAF & $94.6(1.4)$ & $72.5(1.2)$ & 18.3 & 3.6 & 21.9 \\
MAFC & $51.2(2.0)$ & $35.7(2.0)$ & 8.8 & 40.3 & 49.1 \\
\hline \multicolumn{3}{c}{${ }^{*}$ SD, standard deviation. }
\end{tabular}

\subsection{Mechanical Properties of PU Elastomer Composites}

Figure 6 shows the mechanical properties of the composites: (a) tensile strength, (b) tear strength of MAF/PU and MAFC/PU, (c) tensile stress-strain curve of MAF/PU, and (d) tensile stress-strain curve of MAFC/PU. As shown in Figure $6 a, b$, the tensile and tear strength of the MAF/PU and MAFC/PU 
composites increased gradually with the increasing of the filler content because of the strengthening effect of the filler. However, the larger filler content resulted in a greater number of defects in the polyurethane composites, which led to stress concentration and the occurrence of microcracks. Consequently, the tensile and tear strengths declined. Figure $6 \mathrm{a}, \mathrm{b}$ shows that the tensile and tear strengths of the MAF/PU composite with $1 \mathrm{wt} \% \mathrm{MAF}$ reached the maximum values of $30.6 \mathrm{MPa}$ and $70.0 \mathrm{kN} \cdot \mathrm{m}^{-1}$, respectively. In contrast, the MAFC/PU composite had higher tensile and tear strengths with $1 \mathrm{wt} \%$ MAFC content. Furthermore, the tensile and tear strengths of the MAFC/PU composite with $1.5 \mathrm{wt} \%$ MAFC reached maximum values of $36.4 \mathrm{MPa}$ and $80.1 \mathrm{kN} \cdot \mathrm{m}^{-1}$, respectively, corresponding to improvements of $43.3 \%$ and $21.1 \%$. The tensile results indicated that the mechanical properties of the MAFC/PU performed superior to those of the MAF/PU at the same fibrid weight fraction, indicating that the interfacial adhesion between the MAFC and PU matrix was improved by introducing polar groups due to the MAFC surface chlorination treatment. The tensile stress-strain curves of the MAF/PU and MAFC/PU composites are illustrated in Figure $6 \mathrm{c}, \mathrm{d}$, respectively. The MAF/PU and MAFC/PU composites exhibited similar stress-strain behaviors. In the initial stage, the stresses in the PU elastomer composites increased linearly at low strain levels and exhibited a certain rigidity; the stresses in the PU elastomer subsequently began to increase slowly with strain; in the final stage, the stress increased rapidly due to the strain-hardening effect until the polyurethane composites fractured [30]. The stress-strain curve of the MAF/PU composite changed little with the addition of the MAF, whereas the stress-strain curve of the MAFC/PU composite changed significantly with the addition of the MAFC, which indicated that the modified MAFC produced a more pronounced strengthening and toughening effect on the polyurethane elastomers.
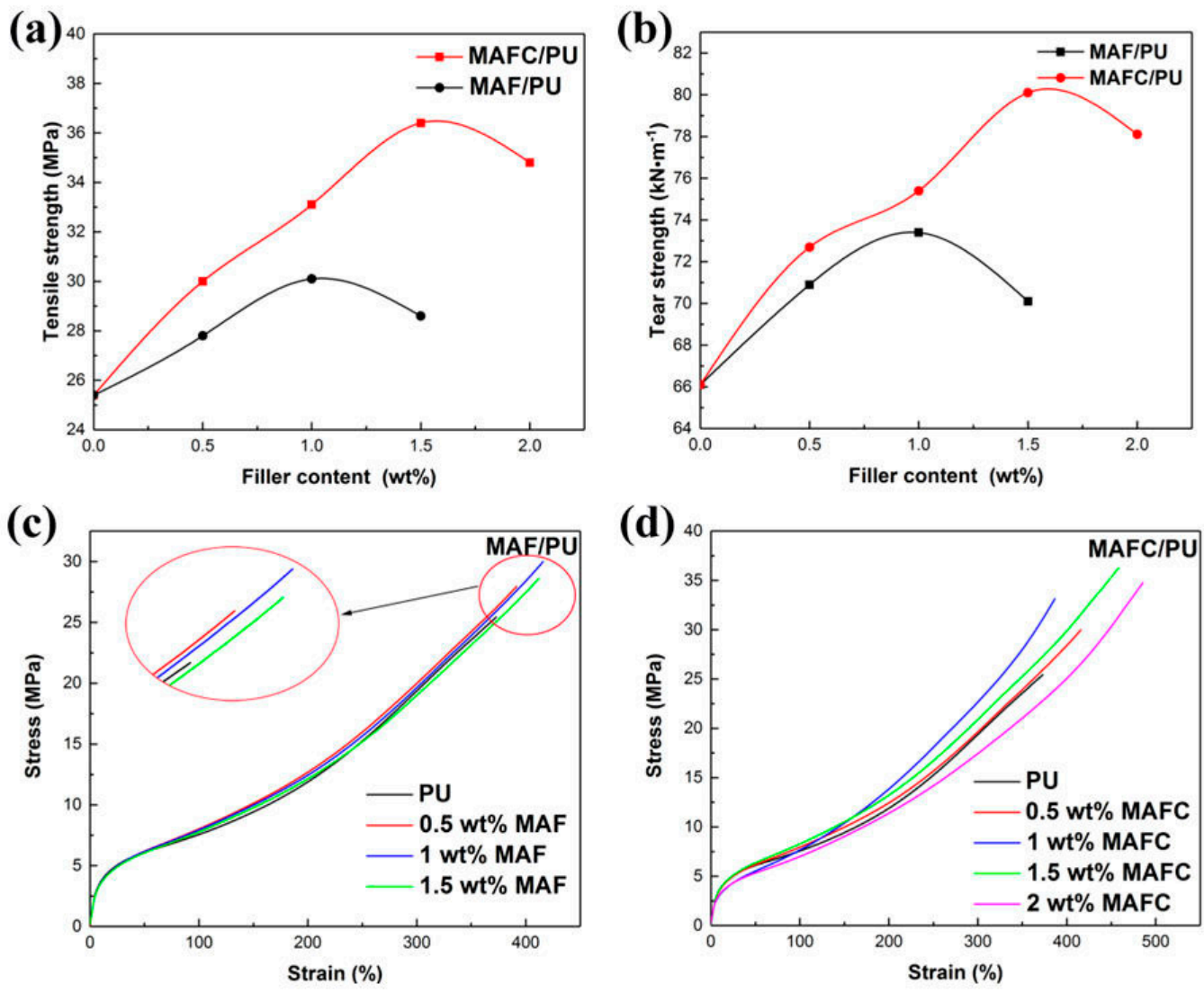

Figure 6. Mechanical properties of the composites: (a) tensile strength, (b) tear strength of $\mathrm{MAF} /$ polyurethane (PU) and MAFC/PU, (c) tensile stress-strain curve of MAF/PU, and (d) tensile stress-strain curve of MAFC/PU. 
Table 4 shows the mechanical properties of the MAF/PU and MAFC/PU composites. The composites were determined by tensile tests. The hardness values, tensile strengths, tear strengths, elongations at the break, 100\% moduli, and 300\% moduli of PU-MAF and PU-MAFC composites were shown in Table 4. The tensile and tear strength of the MAF/PU and MAFC/PU composites were enhanced remarkably. To study the mechanical properties, five specimens were chosen from each of the eight samples.

Table 4. Variations in mechanical properties of polyurethane composites with the increasing modified meta-aramid fibrids content.

\begin{tabular}{cccccccc}
\hline Sample & $\begin{array}{c}\text { Hardness/ } \\
\text { Shore A }\end{array}$ & $\begin{array}{c}\text { Modulus } \\
\text { at 100\%/MPa }\end{array}$ & $\begin{array}{c}\text { Modulus } \\
\text { at 300\%/MPa }\end{array}$ & $\begin{array}{c}\text { Tensile } \\
\text { Strength/MPa }\end{array}$ & $\begin{array}{c}\text { Elongation } \\
\text { at Break/\% }\end{array}$ & $\begin{array}{c}\text { Tear } \\
\text { Strength/kN.m } \mathbf{~}^{-1}\end{array}$ & $\begin{array}{c}\text { Rebound } \\
\text { Rate/\% }\end{array}$ \\
\hline PU & $86(1)$ & $5.6(0.2)$ & $9.0(0.4)$ & $25.4(1.3)$ & $373(20)$ & $66.1(1.2)$ & $40(1)$ \\
P-F-0.5 & $87(1)$ & $5.7(0.1)$ & $8.6(0.4)$ & $27.8(0.9)$ & $391(15)$ & $68.9(0.8)$ & $40(2)$ \\
P-F-1 & $88(2)$ & $5.0(0.3)$ & $8.0(0.2)$ & $30.1(2.0)$ & $415(16)$ & $70.0(1.1)$ & $39(1)$ \\
P-F-1.5 & $85(1)$ & $5.8(0.4)$ & $8.8(0.6)$ & $28.6(1.8)$ & $412(21)$ & $68.1(2.0)$ & $38(1)$ \\
P-FC-0.5 & $87(1)$ & $5.9(0.2)$ & $9.6(0.5)$ & $30.0(1.5)$ & $416(19)$ & $72.7(1.6)$ & $39(1)$ \\
P-FC-1 & $88(1)$ & $6.0(0.3)$ & $10.1(0.4)$ & $33.1(2.1)$ & $387(22)$ & $75.4(2.0)$ & $38(1)$ \\
P-FC-1.5 & $89(2)$ & $6.2(0.4)$ & $10.4(0.2)$ & $36.4(1.4)$ & $458(18)$ & $80.1(1.9)$ & $38(2)$ \\
P-FC-2 & $88(1)$ & $6.2(0.3)$ & $10.5(0.3)$ & $34.8(1.9)$ & $485(20)$ & $78.1(2.3)$ & $37(1)$ \\
\hline
\end{tabular}

\subsection{Morphologies of MAFC/PU Composites}

To observe the distribution of the MAFC in the MAFC/PU composites, the ends of the MAFC/PU composite samples were immersed in a 50\% sulfuric acid solution for $30 \mathrm{~min}$, and the surface polyurethane was etched to expose the internal MAFC. Figure 7 shows the SEM images of the surface etching morphology of the MAFC/PU composites. As shown in Figure 7a, the distribution of MAFC in the PU-FC-1.5 was visible after etching the polyurethane (PU). The MAFC was distributed as a disordered manner in the MAFC/PU composites, and no physical cross-linking was found between the MAFC. As shown in Figure 7b, the surface of the MAFC of the MAFC/PU composite was covered with a layer of polyurethane, which indicated that the chlorinated MAFC has better interfacial adhesion with the polyurethane matrix due to the improvement of wettability after the chlorination modification.
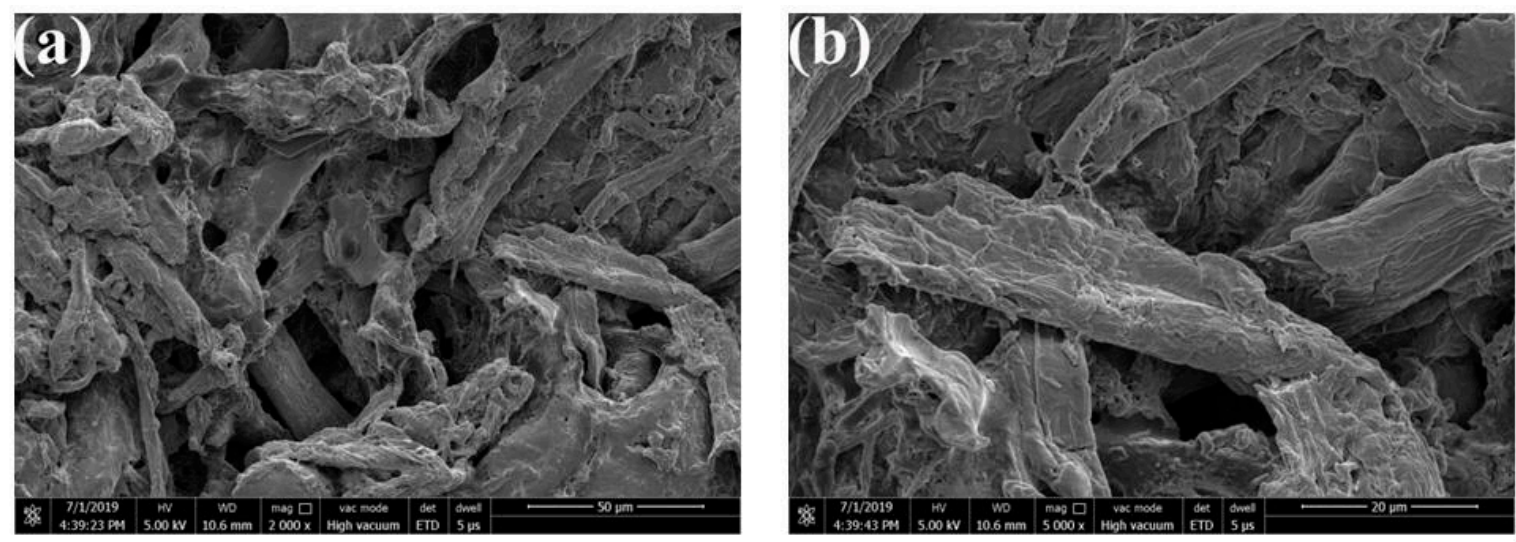

Figure 7. SEM images of surfaces etching of MAFC/PU in $1.5 \mathrm{wt} \%$ of the MAFC weight content (PU-FC-1.5) with (a) magnification at 2000, and (b) magnification at 5000.

\section{Conclusions}

It can be concluded that a novel chlorination treatment of MAF was investigated in this study. By employing this methodology, certain chlorine-containing chemical groups, $\mathrm{O}=\mathrm{C}-\mathrm{N}-\mathrm{Cl}$ and $\mathrm{C}_{6} \mathrm{H}_{5} \mathrm{Cl}$, were formed on the surfaces of the MAF due to the $\mathrm{N}$-chlorination reaction of amide nitrogen and the Orton rearrangement of $\mathrm{O}=\mathrm{C}-\mathrm{N}-\mathrm{Cl}$, respectively, which changed the polarities of the fibers significantly. The surface wettability and surface free energy of the MAF was improved extensively, 
which was beneficial for forming a stronger chemical bond between the MAF and polyurethane matrix. Therefore, the mechanical properties of the polyurethane reinforced with the chlorination modified MAF (MAFC) were better than those of the MAF/PU composites. Thus, this is a novel method for obtaining high-performance polyurethane.

Author Contributions: Conceptualization, Y.Y. and M.G.; Data curation, W.L., C.N., and J.A.S.M.; Formal analysis, Y.Y., C.N., and J.A.S.M.; Funding acquisition, Y.Y.; Investigation, W.L., Y.Y., C.N., and M.G.; Methodology, W.L., Y.Y., C.N., and M.G.; Project administration, Y.Y.; Resources, Y.Y. and M.G.; Software, J.A.S.M.; Supervision, Y.Y.; Validation, C.N. and M.G.; Visualization, W.L., Y.Y., C.N. and J.A.S.M.; Writing-original draft, W.L.; Writing-review and editing, J.A.S.M.

Funding: The authors gratefully acknowledge the financial support of this research work by the Natural Science Foundation of Guangdong Province Project (project number 2016A030313520), Key Laboratory of Polymeric Composite and Functional Materials of Ministry of Education Project (project number PCFM-2017-02), Guangdong Water Conservancy Science and Technology Innovation Project (project number 2017-24), and the Guangdong Provincial Department of Education Featured Innovation Project (project number 2017KTSCX007).

Acknowledgments: The authors are grateful to the reviewers for their valuable review comments to enrich the publication.

Conflicts of Interest: The authors declare no conflict of interest. The funders had no role in the design of the study; in the collection, analyses, or interpretation of data; in the writing of the manuscript, and in the decision to publish the results.

\section{References}

1. Beck, R.A.; Truss, R.W. The effect of curative on the fracture toughness of PTMEG/TDI polyurethane elastomers. Polymer 1995, 36, 767-774. [CrossRef]

2. Raftopoulos, K.N.; Janowski, B.; Apekis, L.; Pielichowski, K.; Pissis, P. Molecular mobility and crystallinity in polytetramethylene ether glycol in the bulk and as soft component in polyurethanes. Eur. Polym. J. 2011, 47, 2120-2133. [CrossRef]

3. Jenkins, M.J.; Cao, Y.; Kukureka, S.N. The effect of molecular weight on the crystallization kinetics and equilibrium melting temperature of poly(tetramethylene ether glycol). Polym. Adv. Technol. 2006, 17, 1-5. [CrossRef]

4. Fritz Fidel Rocco, J.A.; Salgueiro Lima, J.E.; Lourenco, V.L.; Batista, N.L.; Botelho, E.C.; Iha, K. Dynamic mechanical properties for polyurethane elastomers applied in elastomeric mortar. J. Appl. Polym. Sci. 2012, 126, 1461-1467. [CrossRef]

5. Dutta, S.; Karak, N.; Baruah, S. Jute-fiber-reinforced polyurethane green composites based on Mesua ferrea L. seed oil. J. Appl. Polym. Sci. 2010, 115, 843-850. [CrossRef]

6. Lei, W.; Fang, C.; Zhou, X.; Li, Y.; Pu, M. Polyurethane elastomer composites reinforced with waste natural cellulosic fibers from office paper in thermal properties. Carbohydr. Polym. 2018, 197, 385-394. [CrossRef] [PubMed]

7. Sair, S.; Oushabi, A.; Kammouni, A.; Tanane, O.; Abboud, Y.; El Bouari, A. Mechanical and thermal conductivity properties of hemp fiber reinforced polyurethane composites. Case Studies Constr. Mater. 2018, 8, 203-212. [CrossRef]

8. Zhang, Y.; Zhang, Y.; Liu, Y.; Wang, X.; Yang, B. A novel surface modification of carbon fiber for high-performance thermoplastic polyurethane composites. Appl. Surf. Sci. 2016, 382, 144-154. [CrossRef]

9. Han, D.; Park, I.; Kim, M.; Noh, B.; Kim, W.; Lee, J. The effects of glass fiber reinforcement on the mechanical behavior of polyurethane foam. J. Mech. Sci. Technol. 2010, 24, 263-266. [CrossRef]

10. Shibulal, G.S.; Naskar, K. Structurally different short aramid fiber-reinforced thermoplastic polyurethane. Polym. Compos. 2014, 35, 1767-1778. [CrossRef]

11. Yao, L.; Kim, K.; Kim, J. Fabrication of meta-aramid fibrid by precipitation. Fibers. Polym. 2012, 13, $277-281$. [CrossRef]

12. Yao, L.; Li, X.; Jiang, Y. A mathematical model of meta-aramid fibrid formation. Therm. Sci. 2017, 4, 1651-1655. [CrossRef]

13. Zhang, S.; Zhang, M.; Li, K. Adhesion force between aramid fibre and aramid fibrid by AFM. Polym. Bull. 2011, 66, 351-362. [CrossRef] 
14. Zhao, H.; Zhu, Y.; Sha, L. Study of the relationship between characteristics of aramid fibrids and mechanical property of aramid paper using DSC. E-Polymers 2014, 14, 139-144. [CrossRef]

15. Chen, X.; Wang, W.; Jiao, C. A recycled environmental friendly flame retardant by modifying para-aramid fiber with phosphorus acid for thermoplastic polyurethane elastomer. J. Hazard. Mater. 2017, 331, 257-264. [CrossRef]

16. Xu, D.; Yu, K.; Qian, K. Effect of tris(1-chloro-2-propyl)phosphate and modified aramid fiber on cellular structure, thermal stability and flammability of rigid polyurethane foams. Polym. Degrad. Stab. 2017, 144, 207-220. [CrossRef]

17. Zhao, J. Effect of surface treatment on the structure and properties of para-aramid fibers by phosphoric acid. Fibers. Polym. 2013, 14, 59-64. [CrossRef]

18. Xu, D.; Yu, K.; Qian, K. Thermal degradation study of rigid polyurethane foams containing tris(1-chloro-2-propyl)phosphate and modified aramid fiber. Polym. Test. 2018, 67, 159-168. [CrossRef]

19. Gao, J.; Dai, Y.; Wang, X.; Huang, J.; Yao, J.; Yang, J.; Liu, X. Effects of different fluorination routes on aramid fiber surface structures and interlaminar shear strength of its composites. Appl. Surf. Sci. 2013, 270, 627-633. [CrossRef]

20. Maity, J.; Jacob, C.; Das, C.K.; Kharitonov, A.P.; Singh, R.P.; Alam, S. Fluorinated aramid fiber reinforced polypropylene composites and their characterization. Polym. Compos. 2007, 28, 462-469. [CrossRef]

21. Tarantili, P.A.; Andreopoulos, A.G. Mechanical properties of epoxies reinforced with chloride-treated aramid fibers. J. Appl. Polym. Sci. 1997, 65, 267-276. [CrossRef]

22. Jia, C.; Chen, P.; Liu, W.; Li, B.; Wang, Q. Surface treatment of aramid fiber by air dielectric barrier discharge plasma at atmospheric pressure. Appl. Surf. Sci. 2011, 257, 4165-4170. [CrossRef]

23. Yang, T.; Han, E.; Wang, X.; Wu, D. Surface decoration of polyimide fiber with carbon nanotubes and its application for mechanical enhancement of phosphoric acid-based geopolymers. Appl. Surf. Sci. 2017, 416, 200-212. [CrossRef]

24. Ahn, D.; Lee, J.; Kang, C. Physico-chemical properties of new composite polymer for heat resistance with thin-film form through the blending of m-aramid and polyurethane (PU). Polymer 2018, 138, 17-23. [CrossRef]

25. Kang, G.; Gao, C.; Chen, W.; Jie, X.; Cao, Y.; Yuan, Q. Study on hypochlorite degradation of aromatic polyamide reverse osmosis membrane. J. Membr. Sci. 2007, 300, 165-171. [CrossRef]

26. Xu, J.; Wang, Z.; Wei, X.; Yang, S.; Wang, J.; Wang, S. The chlorination process of crosslinked aromatic polyamide reverse osmosis membrane: New insights from the study of self-made membrane. Desalination 2013, 313, 145-155. [CrossRef]

27. Do, V.T.; Tang, C.Y.; Reinhard, M.; Leckie, J.O. Degradation of polyamide nanofiltration and reverse osmosis membranes by hypochlorite. Environ. Sci. Technol. 2011, 46, 852-859. [CrossRef]

28. Shao, Q.; Bai, R.; Tang, Z.; Pang, H.; Yan, W.; Sun, J.; Ren, M. Preparation of silver-deposited aromatic polysulfonamide fibers with excellent performance via electroless nanoplating using a chlorine-aided silver activation system. Ind. Eng. Chem. Res. 2015, 54, 11302-11311. [CrossRef]

29. Shao, F.; Dong, L.; Dong, H.; Zhang, Q.; Zhao, M.; Yu, L.; Pang, B.; Chen, Y. Graphene oxide modified polyamide reverse osmosis membranes with enhanced chlorine resistance. J. Membr. Sci. 2017, 525, 9-17. [CrossRef]

30. Amornsakchai, T.; Sinpatanapan, B.; Bualek-Limcharoen, S.; Meesiri, W. Composite of aramid fibre (poly-m-phenylene isophthalamide)-thermoplastic elastomers (SEBS): Enhancement of tensile properties by maleated-SEBS compatibiliser. Polymer 1999, 40, 2993-2999. [CrossRef]

(C) 2019 by the authors. Licensee MDPI, Basel, Switzerland. This article is an open access article distributed under the terms and conditions of the Creative Commons Attribution (CC BY) license (http://creativecommons.org/licenses/by/4.0/). 